\title{
Sometimes, Faculty Matter: The Contribution of Faculty Support to Future Engagement
}

\section{Dr. Denise Wilson, University of Washington}

Denise Wilson is a professor of electrical engineering at the University of Washington, Seattle. Her research interests in engineering education focus on the role of self-efficacy, belonging, and other noncognitive aspects of the student experience on engagement, success, and persistence.

Prof. Diane Carlson Jones Ph.D, University of Washington

Prof. Rebecca A Bates, Minnesota State University, Mankato

Rebecca A. Bates received the Ph.D. degree in electrical engineering from the University of Washington in 2004. She also received the M.T.S. degree from Harvard Divinity School in 1993. She is currently Professor and Chair of the Department of Integrated Engineering program at Minnesota State University, Mankato, home of the Iron Range and Twin Cities Engineering programs.

\section{Dr. Tamara Floyd Smith, Tuskegee University}

Dr. Tamara Floyd Smith is a Professor of Chemical Engineering at Tuskegee University.

\section{Dr. Melani Plett, Seattle Pacific University}

Prof. Melani Plett is a Professor in Electrical Engineering at Seattle Pacific University. She has over seventeen years of experience in teaching a variety of engineering undergraduate students (freshman through senior) and has participated in several engineering education research projects, with a focus how faculty can best facilitate student learning.

\section{Dr. Nanette M Veilleux, Simmons College}

Nanette Veilleux is a Professor and Director of the Computer Science and Informatics Program at Simmons College, Boston, MA. Her research interests include pedagogy in STEM disciplines, particularly with respect to women students and computational linguistics where she investigates the use of intonation in human speech. 


\title{
Sometimes, Faculty Matter: The Contribution of Faculty Support to Future Engagement
}

\begin{abstract}
In this study, we examine the contribution of student-faculty interactions to the future engagement of students in their academic endeavors. These relationships were evaluated in a one-year longitudinal study of STEM (including engineering and computer science) students at five different institutions. These five institutions include three types of Carnegie 2010 classifications (Bac-Diverse, Master's L, and RU-VH), four geographical locations including the northwest, northeast, midwest, and southeast, and both public and private institutions with total undergraduate enrollments varying from 1,900 to 29,000 students. Both behavioral (effort, participation) and emotional (positive, negative) aspects of engagement are studied. Results show that significant relationships emerged for three of the five schools between faculty support and engagement. Formal faculty support (that provided in the context of a particular course) predicted effort (a form of behavioral engagement) at the HBCU in this study and also positive emotional engagement for both the HBCU and Teaching institution. Informal faculty support (that provided outside the context of a particular course) predicted participation (another form of behavioral engagement) and positive emotional engagement at the Research institution in the study. These results suggest that institutional culture influences how what faculty do predicts future engagement outcomes for students. At the Research institution, it appears that what happens between faculty and students outside of class influences students while at smaller or teaching-oriented institutions, what faculty do inside a class matters more. These results can provide important insight to faculty as to how to guide their interactions with students at different institutions to make the most difference in students' academic lives.
\end{abstract}

\section{Introduction}

In this study, we looked at the contribution of faculty support both within the context of a particular course (formal faculty support) and outside that context (informal faculty support) to the future academic engagement of these students in their academic endeavors. We chose constructs of engagement that come from motivational research ${ }^{1,2}$ and include perceived behavioral and affective dimensions ${ }^{1}$. Behavioral engagement captures how involved a student may be in his or her academic endeavors and has included measures of effort and participation in class discussions ${ }^{2}$. In addition to effort and participation, a student's positive and negative feelings about academic experiences can be captured using constructs of positive and negative emotional engagement. Feelings included in these measures can range from feelings of interest and enjoyment to anxiety/worry and discouragement ${ }^{3,4}$. Both behavioral and emotional engagement have been shown to be fundamental to the learning process ${ }^{5,6}$ and thus provide a broader foundation for understanding the dynamics of learning in the college classroom.

Longitudinal relationships between faculty support and behavioral and emotional engagement were evaluated in a one-year longitudinal study of engineering and computer science students at five different institutions. These five institutions include three types of Carnegie 2010 classifications $^{6}$ (Bac-Diverse, Master's L, and RU-VH), four geographical locations including the northwest, northeast, midwest, and southeast, and both public and private institutions with total undergraduate enrollments varying from 1,900 to 29,000 students. 


\section{Background}

The positive relationship between student-faculty support and academic outcomes for students has been established in the literature. Although somewhat dated, Lamport's review ${ }^{8}$ highlights the multi-dimensional importance of student-faculty interactions. Faculty-student interactions are significantly associated with satisfaction in college. They also predict increases in cognitive ability, personal identity, and values, and support integration into the institution, thereby reducing the risk of dropping out of school. Moreover, it has been shown that it is not the quantity of student-faculty interactions but the quality of the relationships that makes a difference, so much so that a strong relationship with a faculty member can override the effects of student culture $^{8}$. More recent research studies reinforce the importance of the student-faculty relationship. For example, in a study of over 4,500 students at various doctoral and master's level institutions, Lundberg and Schreiner ${ }^{9}$ found that the quality of faculty-student relationships significantly predicted learning for all ethnic groups. In a much broader study of over 43,000 students from 119 majors across nine campuses, Kim and $\mathrm{Sax}^{10}$ report that students' contact with faculty and undergraduate research engagement were significantly related to their cognitive development. In a smaller study of approximately 200 students at a single institution, Halawah ${ }^{11}$ provides evidence that both faculty concern and informal faculty relations were significantly correlated to intellectual development. Although these results were significant across all majors, a positive departmental climate of faculty support, as well as clear, organized department policies strengthened the relationship between faculty interactions and cognitive development. In particularly challenging courses like organic chemistry, student-faculty relationships were also significantly related to grades as well as course confidence ${ }^{12}$. In engineering, faculty and department support was one of four key factors in supporting the ability of under-represented minorities to develop a sense of community and belonging ${ }^{13}$. Highlighting the importance of faculty involvement, Lundberg and Schreiner ${ }^{9}$ found that interactions and relationships with faculty were stronger predictors of student learning than race and ethnicity.

Although the body of research on faculty support in higher education is significant, studies of the relationship between faculty support and engagement are notably absent from the higher education literature, particularly in engineering education research. This work seeks to address this gap, in part, by studying the relationship between faculty support (both formal and informal) and behavioral and emotional engagement, because the latter constructs reflect the motivational state of the student and motivation is an important predictor of present as well as future behavior.

\section{Methods}

This research is part of a larger five-year, multiple institution research study that examines connection, community, and engagement in STEM education. In this larger study (described elsewhere ${ }^{14}$ ), patterns of belonging, connection to community, and related affective outcomes are investigated with the goal of predicting and improving engagement and connection to community across a diverse range of institutions, students, teaching styles, and faculty. We are currently in the last year of this broader study funded by the National Science Foundation.

This part of the study focuses on understanding how faculty support provided as part of a class (formal faculty support) and provided more generally (informal faculty support) predicts future 
engagement of STEM students (including significant number of engineering and computer science majors). Data are collected from the following five institutions:

- HBCU (Bac-Div): A historically black, independent, and state-related institution of 2,605 undergraduates in the Southeast which offers four undergraduate engineering degrees and is typically characterized by small groups of students (class sizes of 5-50). Students can begin the engineering curriculum as early as first semester freshman year.

- Private/Faith Based (Masters L): A small teaching institution in the Pacific Northwest of 3,238 undergraduates, whose mission emphasizes building graduates of competence and character by providing tools of rigorous learning and modeling a grace-filled community. This institution offers six engineering and computer science majors that are based on and informed by a Christian world view. Class sizes typically range from 15-20.

- Research (RU/VH): A large research institution and flagship university in the Pacific Northwest which serves over 29,000 undergraduates and confers over 12,000 degrees annually. This institution offers ten engineering and computer science undergraduate degrees, and is characterized by large classes in freshman and sophomore years (100-500) and smaller classes in junior (40-80 students) and senior (15-40 students) year. Most students are competitively admitted to engineering and computer science majors after their second year.

- Teaching (Masters L): A medium-sized institution of approximately 13,504 undergraduates in the Midwest that combines an emphasis on teaching with emerging innovations in research, serving a regional student population. This institution offers over ten undergraduate degrees in engineering and computer science. Class sizes typically average 25 students, with upper division classes averaging about 15 students.

- Women's (Masters L): A small women's college of approximately 1,792 undergraduates in the Northeast with fifty majors, including computer science, biology, biochemistry, biostatistics, chemistry, environmental science, health informatics, mathematics, and physics degrees in STEM, but no engineering degrees. This institution offers a liberal arts education for its undergraduates integrated with professional work experience. Class sizes are typically 6-12 students, with the largest class size around 20.

This research uses a longitudinal quantitative methods approach that looks at the predictive influence of faculty support on future academic engagement. Although indirect relationships between faculty support and engagement may be present through such intermediate outcomes as belonging or connections to community, the focus of this study remains on direct relationships between these two primary constructs. The pathways we study herein are highlighted in yellow in Figure 1. 


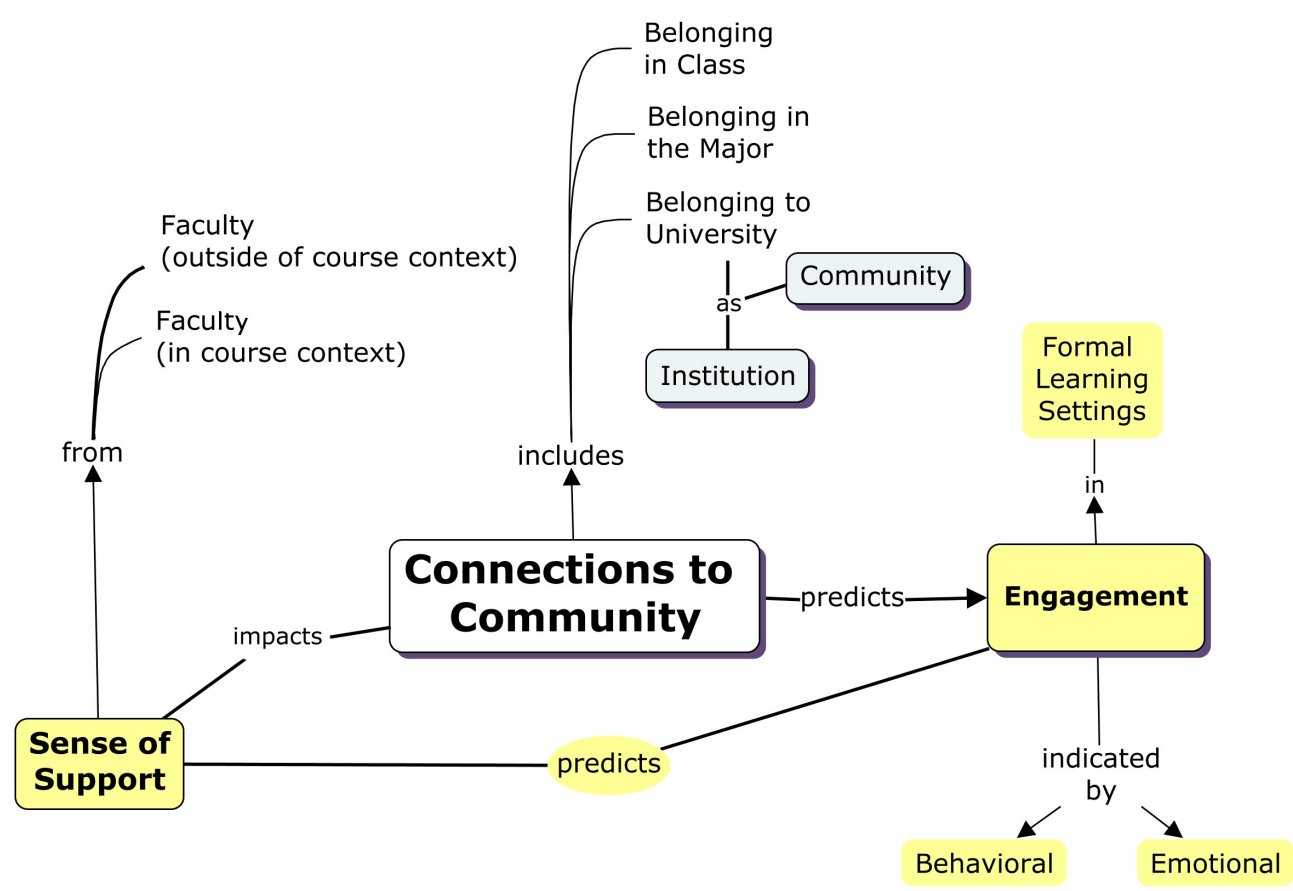

Figure 1: Conceptual Model used in this Study

This analysis emphasizes the direct connections between faculty support and engagement.

\section{A. Research Questions}

Two research questions were addressed in this part of our study.

\section{Research Question \#1:}

Does formal faculty support predict future behavioral or emotional engagement?

This question provides some insight as to the impact of what faculty do in classes. Longitudinal relationships between what faculty do in the classroom and future behavioral and emotional engagement give some indication as to the staying power of what faculty do in individual classes with regard to changing student behavior and motivation over the long term.

\section{Research Question \#2:}

Does informal faculty support predict future behavioral or emotional engagement?

This question provides valuable contrast to what faculty do in the context of individual courses compared to what they do in general, outside of the classroom, to interact with, relate to, and support students. Longitudinal relationships between informal faculty support and future student engagement speak to the impact of less formal learning communities and experiences, including but not limited to undergraduate research and design competitions, as well as truly informal interactions that occur in hallways, offices, and in spaces where faculty and students run into each other every day.

\section{B. Subjects and Procedures}

Undergraduate students in a variety of engineering, computer science, and other science majors in STEM were recruited for this study. A sample of convenience including over 1507 students began participation in this study by completing a survey of their experiences, including 
participation in communities both inside and outside of school, their feelings about the degree to which they belong (or do not belong) in these communities, and a variety of other demographics and affective indicators. Survey participants were recruited to complete a hard copy of the survey in core classes (those required by the student's major) by researchers on each of the five campuses during the Fall 2010 and Spring 2011 terms (Time 1 - T1). Additional T1 students were recruited as needed (to achieve a larger sample size) by e-mail using an electronic version of the survey and using similar recruitment protocols as with on-paper surveys. Approximately one year later $($ Mean $=12.5$ months; range $=9.5-15$ months), students were contacted again and asked to complete an electronic follow-up survey (Time 2-T2). Approximately one-third of the original sample $(32 \% ; \mathrm{N}=482)$ provided survey responses within the specified time range. Demographics of the longitudinal population are described in Table 1.

Table 1: Longitudinal Study Demographics

\begin{tabular}{c|c|c|c|c|c|c|c}
\hline Institution & $\begin{array}{c}\text { Total } N \\
(\%)\end{array}$ & Men & Women & Asian & Black & Hisp & White \\
\hline HBCU & $75(16 \%)$ & $59 \%$ & $41 \%$ & $0 \%$ & $91 \%$ & $0 \%$ & $0 \%$ \\
\hline Private & $32(6.6 \%)$ & $62 \%$ & $38 \%$ & $9.4 \%$ & $0 \%$ & $3.1 \%$ & $78 \%$ \\
\hline Teaching & $99(21 \%)$ & $90 \%$ & $9.6 \%$ & $5.8 \%$ & $2.9 \%$ & $1.9 \%$ & $83 \%$ \\
\hline Research & $241(50 \%)$ & $36 \%$ & $64 \%$ & $31 \%$ & $1.7 \%$ & $1.3 \%$ & $54 \%$ \\
\hline Women's & $35(7.3 \%)$ & $0 \%$ & $100 \%$ & $14 \%$ & $0 \%$ & $2.9 \%$ & $71 \%$
\end{tabular}

\section{Instruments}

Survey data were used to answer both research questions in this study. Additional information regarding this survey is described elsewhere ${ }^{14}$. In the survey, students completed Likert scale questions regarding perceived levels of informal faculty support, formal faculty support, behavioral effort, behavioral participation, positive emotional engagement, and negative emotional engagement. Items included in each scale and corresponding reliabilities are summarized in Table 2.

\section{Data Analysis}

Simultaneous multiple regression analyses were conducted using SPSS18 to test the relationships between informal and formal faculty support and the four measures of academic engagement. Mahalanobis and Cook's distances were evaluated to determine the presence of outliers in the data $\operatorname{set}^{17}$. Although some cases were identified as outliers, the removal of these cases did not significantly impact the results.

The primary analyses employed simultaneous multiple regression analyses using SPSS 18. Four separate multiple regression models evaluated the unique contributions of the T1 Formal and Informal Faculty Support to the T2 behavioral (Effort and Participation) and T2 emotional (Positive and Negative) engagement variables for each school. The appropriate T1 engagement variable was also included in each model to control for the initial level of engagement. Four models were tested on each school separately (for a total of 20 models) in order to evaluate the significance of the faculty support factors to the multiple indicators of T2 engagement for each school and to assess the patterns of significance across the schools. This approach allowed us to evaluate the significance of the model for each school with the greatest clarity regardless of size. 
As such, the school differences in the absolute levels of the standardized regression coefficients were not tested directly and were not central to our goal of assessing the patterns of significance across schools. Statistical significance of each regression model and each predictor was determined by $p$ levels set at the standard $<.05$ for social science research.

Table 2: Items, Scales, and Reliabilities of Interest to this Study

\begin{tabular}{|c|c|c|}
\hline Scale & Items (Measured on 5-Point Likert Scale) & Reliability \\
\hline $\begin{array}{l}\text { Faculty Support } \\
\qquad(\text { Formal })^{15}\end{array}$ & $\begin{array}{l}\text { The instructor in this class is willing to spend time outside of } \\
\text { class to discuss issues that are of interest and importance to me. } \\
\text { The instructor in this class is interested in helping me learn. } \\
\text { The instructor in this class cares about how much I learn. } \\
\text { The instructor in this class treats me with respect. }\end{array}$ & 0.89 \\
\hline $\begin{array}{l}\text { Faculty Support } \\
{\text { (Informal })^{16}}^{\text {(I) }}\end{array}$ & $\begin{array}{l}\text { Since coming to this university I have developed a supportive } \\
\text { relationship with at least one faculty member. } \\
\text { My non-classroom interactions with instructors have had a } \\
\text { positive influence on my personal growth, values, and attitudes. } \\
\text { My non-classroom interactions with faculty have had a positive } \\
\text { influence on my career goals and aspirations. } \\
\text { My non-classroom interactions with faculty have had a positive } \\
\text { influence on my intellectual growth and interest in ideas. }\end{array}$ & 0.88 \\
\hline $\begin{array}{l}\text { Behavioral } \\
\text { Engagement } \\
\quad(\text { Effort })^{4}\end{array}$ & $\begin{array}{l}\text { I try hard to do well in my major classes. } \\
\text { In my major classes, I work as hard as I can. } \\
\text { In my lab/study groups, I work as hard as I can. } \\
\text { I try hard to do well in this class. } \\
\text { In this class, I work as hard as I can. }\end{array}$ & 0.86 \\
\hline $\begin{array}{c}\text { Behavioral } \\
\text { Engagement } \\
{\text { (Participation })^{4}}^{4}\end{array}$ & $\begin{array}{l}\text { When I'm in classes in my major, I participate in class } \\
\text { discussions with my classmates and instructors. } \\
\text { When I'm in this class, I participate in class discussions with my } \\
\text { classmates and instructors }\end{array}$ & 0.74 \\
\hline $\begin{array}{l}\text { Emotional } \\
\text { Engagement } \\
{\text { (Positive })^{4}}^{\text {Pos }}\end{array}$ & $\begin{array}{l}\text { I enjoy learning new things in my major classes. } \\
\text { When I'm in classes in my major, I feel good. } \\
\text { In my major classes, when we work on something I feel } \\
\text { interested. } \\
\text { In my lab/study groups, when we work on something I feel } \\
\text { interested. } \\
\text { My lab/study groups are fun. } \\
\text { I enjoy learning new things in my lab/study group }\end{array}$ & 0.84 \\
\hline $\begin{array}{l}\text { Emotional } \\
\text { Engagement } \\
\text { (Negative) }^{4}\end{array}$ & $\begin{array}{l}\text { When I'm in classes in my major, I feel worried. } \\
\text { When we work on something in my lab/study groups, I feel } \\
\text { discouraged. } \\
\text { When I'm in my lab/study groups, I feel worried. } \\
\text { When I'm in this class, I feel worried. } \\
\text { In this class, when we work on something in class I feel } \\
\text { discouraged. }\end{array}$ & 0.83 \\
\hline
\end{tabular}




\section{Results and Discussion}

A summary of the models used in this regression analysis along with their significance can be found in Table 3. Detailed results and parameters for each of the 20 regression models are found in the Appendix. While the models associated with the HBCU, Research, and Teaching institutions were significant for all four forms of engagement, corresponding models for the smaller schools (Private and Women's) were often not significant, due at least in part to the limited longitudinal sample size (32 at the Private institution and 35 at the Women's institution).

Table 3: Summary of Regression Models Parameters and Significance

\begin{tabular}{|c|c|c|c|c|c|}
\hline Institution & Dependent Variable & $\mathrm{N}$ & $\mathrm{R}^{2}$ & $\mathrm{~F}$ & $p$ \\
\hline $\mathrm{HBCU}$ & \multirow{5}{*}{$\begin{array}{c}\text { Behavioral Engagement } \\
\text { (Effort) }\end{array}$} & 72 & 0.380 & 3.93 & 0.012 \\
\hline Private & & 32 & 0.199 & 2.31 & 0.100 \\
\hline Teaching & & 99 & 0.224 & 9.13 & 0.000 \\
\hline Research & & 240 & 0.263 & 27.5 & 0.000 \\
\hline Women's & & 35 & 0.039 & 12.3 & 0.060 \\
\hline $\mathrm{HBCU}$ & \multirow{5}{*}{$\begin{array}{c}\text { Behavioral Engagement } \\
\text { (Participation) }\end{array}$} & 72 & 0.242 & 7.24 & 0.000 \\
\hline Private & & 32 & 0.221 & 2.64 & 0.070 \\
\hline Teaching & & 99 & 0.236 & 9.80 & 0.000 \\
\hline Research & & 240 & 0.272 & 29.4 & 0.000 \\
\hline Women's & & 35 & 0.480 & 9.58 & 0.000 \\
\hline $\mathrm{HBCU}$ & \multirow{5}{*}{$\begin{array}{c}\text { Emotional Engagement } \\
\text { (Positive) }\end{array}$} & 72 & 0.344 & 11.91 & 0.000 \\
\hline Private & & 32 & 0.155 & 1.71 & 0.188 \\
\hline Teaching & & 99 & 0.270 & 11.83 & 0.000 \\
\hline Research & & 240 & 0.232 & 23.82 & 0.000 \\
\hline Women's & & 35 & 0.378 & 6.29 & 0.002 \\
\hline $\mathrm{HBCU}$ & \multirow{5}{*}{$\begin{array}{c}\text { Emotional Engagement } \\
\text { (Negative) }\end{array}$} & 72 & 0.247 & 7.45 & 0.000 \\
\hline Private & & 32 & 0.253 & 3.16 & 0.040 \\
\hline Teaching & & 99 & 0.149 & 5.61 & 0.001 \\
\hline Research & & 240 & 0.235 & 24.13 & 0.000 \\
\hline Women's & & 35 & 0.473 & 9.28 & 0.000 \\
\hline
\end{tabular}

The significant relationships between the individual predictors in the regression models and the engagement factors are summarized in Figure 2. The detailed parameters for each model are provided in the Appendix. 


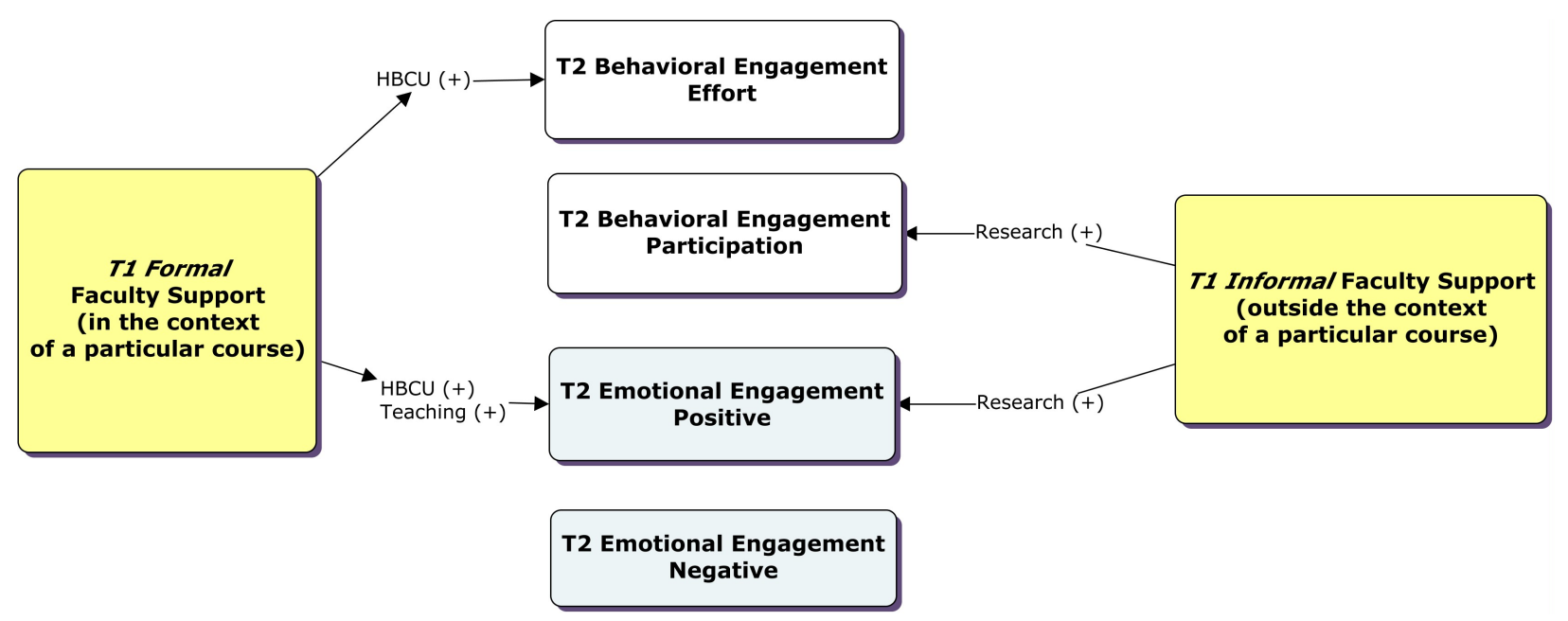

Figure 2: Longitudinal Results

Longitudinal relationships between formal faculty support and informal faculty support (independent $\mathrm{T} 1$ variables) and four types of academic engagement (dependent $\mathrm{T} 2$ variables) were studied while controlling for engagement at $\mathrm{T} 1$. The pattern of results revealed that the $\mathrm{T} 1$ engagement variables were the most consistent and generally strongest predictors of the T2 engagement variables in 15 of the 16 significant regression models. These findings suggest that T1 participation, effort, and positive and negative emotional engagement are relatively stable characteristics in the self-perceptions of students.

Table 4: Significant contributions of Faculty Support to Engagement

\begin{tabular}{|c|c|c|c|c|c|}
\hline \multirow{2}{*}{ Dependent Variable } & \multirow{2}{*}{$\begin{array}{l}\text { Number of } \\
\text { Significant } \\
\text { Models }\end{array}$} & \multicolumn{2}{|c|}{$\begin{array}{l}\text { Formal Faculty Support } \\
\text { is a Significant Predictor }\end{array}$} & \multicolumn{2}{|c|}{$\begin{array}{l}\text { Informal Faculty Support } \\
\text { is a Significant Predictor }\end{array}$} \\
\hline & & \# & $\%$ & \# & $\%$ \\
\hline $\begin{array}{c}\text { Behavioral Engagement } \\
\text { (Effort })\end{array}$ & 3 & 1 & $33 \%$ & 0 & $0 \%$ \\
\hline $\begin{array}{c}\text { Behavioral Engagement } \\
\text { (Participation) }\end{array}$ & 4 & 0 & $0 \%$ & 1 & $25 \%$ \\
\hline $\begin{array}{c}\text { Emotional Engagement } \\
\text { (Positive) }\end{array}$ & 4 & 2 & $50 \%$ & 1 & $25 \%$ \\
\hline $\begin{array}{c}\text { Emotional Engagement } \\
\text { (Negative) }\end{array}$ & 5 & 0 & $0 \%$ & 0 & $0 \%$ \\
\hline Total & 16 & 3 & $18.8 \%$ & 2 & $12.5 \%$ \\
\hline
\end{tabular}

Results also show significant predictive relationships beyond the T1 engagement level that allow us to answer the research questions for three of the five institutions in this study. When considering only those models that were significant (Table 4), of a possible 16 connections between formal faculty support and the four forms of engagement, three significant connections emerged. Only two of 16 possible connections between informal faculty support and the four 
forms of engagement emerged. The lack of connections does not mean that faculty support is not important; instead, our results highlight two important observations. First, students seem to be discerning in how they receive faculty support, how they internalize it, and how they transform it to future changes in their academic engagement. Second, the small sample sizes at smaller institutions arising from both smaller enrollments and the difficulties in retaining students in a longitudinal study (which is an issue at all institutions) impair longitudinal studies in these institutions. Thus, mixed methods studies and triangulation of quantitative and qualitative data are essential to understanding what is going on at a range of institutions, from small to very large.

While these mixed methods approaches to a multiple institution study are part of our larger investigation, only quantitative results are reported herein. In future work, we will triangulate quantitative data collected in this study with qualitative data gathered from interviews and focus groups to more fully understand the complex interactions between faculty support and student engagement at all five participating institutions.

\section{Research Question \#1:}

Does formal faculty support predict future behavioral or emotional engagement?

Based on the reports of the students at the HBCU institution, there are significant links between what the faculty do in class (formal support) and how students evaluate their behavioral engagement one year later. When HBCU students perceived that the faculty in at least one class cared about them and demonstrated concern for their learning at $\mathrm{T} 1$, the students were more likely to report trying harder and investing more effort in their major classes one year later.

Similarly, based on the reports of students at both the Teaching and HBCU institution, there are significant links between what faculty do in class and how students evaluate their emotional engagement one year later. When students at these two institutions perceived that faculty were interested and concerned about their learning in at least one class at $\mathrm{T} 1$, then the students were more likely to report that they were interested and having fun in their major classes one year later.

These results do not prove that formal faculty support is not important at the Private and Women's institutions (the two smallest institutions in the study). The longitudinal sample sizes were small in these schools and clearly affected the possibility of detecting statistical significance in the models and predictors. Qualitative data (not reported here) do suggest that faculty support is strong at both institutions and instrumental to some degree in student satisfaction. However, future work will need to tease out relationships between faculty behavior and student engagement at the smaller institutions through further analysis of this qualitative data.

These results also do not prove that formal faculty support at the Research institution is not important to students' future engagement. In this study, students reported formal faculty support in the context of only one of the classes in their major, but reported engagement in the context of all of their major classes. The Research institution is characterized by a much wider range of classes and variation in faculty members than the other four institutions in this study. Students at smaller institutions experience smaller class sizes than do students at the large, research universities and are more likely to have the same professors within a major department. Conversely, at the Research institution, students are exposed to more faculty and larger class sizes. Thus, it is possible that, in some cases, faculty members did make a difference to future 
engagement in particular classes at the Research institution, but the variance in the data overwhelmed any such connections. Understanding if this is the case would require analyzing qualitative data or quantitatively assessing formal faculty support in more than one class.

In summary, our results show that for institutions where sample size is appreciable and where students come into contact with a relatively small number of faculty teaching their major classes, what faculty do in their classes does indeed predict future academic engagement of these students. The way we have chosen to measure engagement (through behavioral and emotional dimensions) also suggests that greater faculty support in class is improving the motivation of students in their future studies.

\section{Research Question \#2:}

Does informal faculty support predict future behavioral or emotional engagement?

At the research institution, perceived support from faculty outside the classroom at T1 made unique contributions to the students' reported classroom participation and positive emotional engagement one year later. When rephrased in terms of the items used to measure student perceptions, this result means that when a student develops a supportive relationship with at least one faculty member or faculty have a positive influence on a student's career goals and aspirations, then, one year later, students tend to enjoy, feel good about, or be more interested in their major classes, labs, and study groups. They also tend toward participating more in these academic communities.

Engineering students at the Research institution have opportunities to participate in a wide range of activities sponsored or supported by engineering faculty. These opportunities include undergraduate research, design competitions, Engineers without Borders, professional societies, and others. These activities are likely to mimic many characteristics of the small department, small class, or multiple classes with the same professor that are present at the smaller institutions, thus providing students opportunities to interact with faculty more over a longer period of time. The larger classes, shorter terms (quarter rather than semester), and more diverse faculty pool at the Research institution may cause classrooms to appear more impersonal and may not be an ideal arena for developing supportive relationships with faculty members. Faculty-student interactions can be sparse at research institutions ${ }^{18}$. But, co-curricular academic activities can be more personal and more frequent, providing for more meaningful faculty support.

\section{Summary}

In three engineering programs ranging from medium to large at three different institutions, ranging from small to very large, we find evidence that faculty support either in the classroom or outside of class can make a difference in the future engagement of students. These results, however, display distinct features at the three schools and may not represent a global pattern among the five schools in this study or a generalizable difference between research-oriented and teaching-oriented institutions. However, this study has shown that when sample sizes are appreciable, faculty support (formal or informal) does impact at least one form of engagement. These results reinforce other studies of faculty support by adding increased academic engagement (behavioral and emotional) to the list of academic outcomes that are improved by strong faculty support. 


\section{Limitations and Implications}

Limitations: We recognize that in drawing data from only five institutions, the generalizability of our findings may be limited. However, the inclusion of five diverse types of institutions in the study does allow for the representation of a wide range of student experiences. Despite the fact that longitudinal sample sizes were small at two schools and most likely limited the significance of the models obtained from the analyses, patterns of faculty support between research-oriented and teaching-oriented institutions were readily identifiable.

Implications: This study has offered insight into how what faculty do influences student motivation as expressed by behavioral and emotional engagement one year later. At smaller and teaching-oriented institutions, what faculty do in the classroom plays a significant role in engagement, thus calling for faculty at these institutions to focus their resources, interactions, and relationships with students in their courses rather than other venues for maximum benefit. In contrast, informal faculty support makes a significant contribution to student engagement at the Research institution (while formal faculty support does not play a significant role). This finding calls for faculty at research institutions to focus their effort on what happens outside of their courses in terms of mentoring, counseling, and guiding students. This study has also implied that despite the chronically small opportunities for interaction students may have with faculty, especially at research institutions ${ }^{18}$, the support that is provided is still having an impact on student engagement and motivation. In this respect, our study highlights the important (and often disproportionate) role that faculty play in the lives of students.

\section{Concluding Remarks}

We have completed a one-year longitudinal study across five institutions to study whether or not faculty support, both within the context of a course (formal support) and outside of it (informal support) predict academic engagement. However, of the predictions that are significant, formal faculty support seems to be a greater influence at the teaching-oriented schools, while informal faculty support plays a more important role at the research-intensive institution. Furthermore, formal faculty support plays a more important role for behavioral effort and positive emotional engagement, while informal faculty support predicts behavioral participation and positive emotional engagement. No forms of faculty support predict negative emotional engagement, thus implying that students' negative feelings about courses and experiences within their major are more rigid than other forms of engagement. This study has established that faculty support is important, albeit in different ways at different institutions. Future work will include looking at qualitative and descriptive data, also collected in this study, to understand how students process faculty support into greater future engagement and why different forms of faculty support play different roles at different institutions.

\section{Acknowledgements}

The authors would like to gratefully acknowledge the National Science Foundation for their support of this work under the REESE program (grant numbers DRL-0909817, 0910143, 0909659, 0909900, and 0909850). Any opinions, findings, and conclusions or recommendations expressed in this material are those of the author(s) and do not necessarily reflect the views of the National Science Foundation. The authors would also like to acknowledge valuable input from our external advisory board (Robin Adams, Purdue University, Shannon Gilmartin, Stanford University, and Karl Smith, University of Minnesota), helpful discussions with project member 
Don Peter at Seattle Pacific University, and data collection efforts from Ryan Campbell, Jeff Chen, Leah Freed, Xingyi Shi and Michael Weiller at the University of Washington; M. Gabriela Garcia, Jeremy Pincosy, Teresa McNamee and Rachel Sear from Minnesota State University, Mankato; Kathleen Maguire, Lynn Passanisi and Courtney Paull from Simmons College; Caitlin Hawkinson, Whitney Giaimo, Nicole Myr, Kara Pegram, and Yolanda Winberg from Seattle Pacific University; and Nicole Walker and Kala Bean from Tuskegee University.

\section{Bibliography}

1. Fredricks, J. A., Blumenfeld, P. C., \& Paris, A. H. (2004). School engagement: Potential of the concept, state of the evidence. Review of Educational Research, 74(1), 59-109.

2. Gasiewski, J. A., Eagan, M. K., Garcia, G. A., Hurtado, S., \& Chang, M. J. (2012). From gatekeeping to engagement: A multicontextual, mixed method study of student academic engagement in introductory STEM courses. Research in Higher Education, 53(2), 229-261.

3. Connell, J. P., \& Wellborn, J. G. (1991). Competence, autonomy, and relatedness: A motivational analysis of self-system processes. In M. Gunnar \& L. A. Sroufe (Eds.), Minnesota symposium on child psychology (Vol. 23). Chicago: University of Chicago Press.

4. Miserandino, M. (1996). Children who do well in school: Individual differences in perceived competence and autonomy in above-average children. Journal of Educational Psychology, 88(2), 203-214.

5. Rocca, K. A. (2010). Student participation in the college classroom: An extended multidisciplinary literature review. Communication Education, 59(2), 185-213.

6. Sansone, C., \& Thoman, D. B. (2005). Interest as the missing motivator in self-regulation. European Psychologist, 10(3), 175.

7. Carnegie Foundation (2010). The Carnegie Classification of Institutions of Higher Education, http://classifications.carnegiefoundation.org/, 2010, accessed March 2015.

8. Lamport, M. A. (1993). Student-faculty informal interaction and the effect on college student outcomes: A review of the literature. Adolescence, 8(112), 971-990.

9. Lundberg, C. A., \& Schreiner, L. A. (2004). Quality and frequency of faculty-student interaction as predictors of learning: An analysis by student race/ethnicity. Journal of College Student Development, 45(5), 549-565.

10. Kim, Y., \& Sax, L. (2011). Are the effects of student-faculty interaction dependent on academic major? An examination using multilevel modeling. Research in Higher Education, 52(6), 589-615.

11. Halawah, I. (2006). The impact of student-faculty informal interpersonal relationships on intellectual and personal development. College Student Journal, 40(3), 670-678.

12. Micari, M., \& Pazos, P. (2012). Connecting to the professor: Impact of the student-faculty relationship in a highly challenging course. College Teaching, 60(2), 41-47.

13. Litzler, E. (2013). How underrepresented minority engineering students derive a sense of belonging from engineering. In Proceedings of the American Society of Engineering Education ASEE Annual Conference: Atlanta, GA.

14. Floyd-Smith, T., Wilson, D., Campbell, R., Veilleux, N., Bates, R., Plett, M., Scott, E., \& Peter, D. (2010). A multi-institutional study of connection, community, and engagement in STEM education: Conceptual model development. In Proceedings of the ASEE (American Society for Engineering Education) Annual Conference \& Exposition, Louisville, KY.

15. Van Ryzin, M. J., Gravely, A. A., \& Roseth, C. J. (2009). Autonomy, belongingness, and engagement in school as contributors to adolescent psychological well-being. Journal of Youth and Adolescence, $38,1-12$.

16. Pascarella, E. T., \& Terenzini, P. T. (1980). Predicting freshman persistence and voluntary dropout decisions from a theoretical model. Journal of Higher Education, 60-75.

17. Stevens, J. P. (2009). Applied multivariate statistics for the social sciences. New York: Taylor \& Francis. 
18. National Survey on Student Engagement (NSSE) (2006). Engaged learning: Fostering success for all students. Retrieved January 8, 2015, from: http://nsse.iub.edu/NSSE_2006_Annual_Report/

\section{Appendix}

\section{Regression Model Parameters}

B: Unstandardized Coefficient; SE: Standard Error; $\beta$ : Standardized Coefficient

Table 5: Prediction of Behavioral Engagement (Effort) by Faculty Support

\begin{tabular}{|c|c|c|c|c|c|}
\hline & B & SE & $\beta$ & $\mathrm{t}$ & p \\
\hline HBCU Institution (Regression Model) & \multicolumn{5}{|c|}{$\mathrm{R}^{2}=0.38 ; \mathrm{F}=3.93 ; N=72 ; p=0.012$} \\
\hline Constant & 11.7 & 2.83 & 4.16 & 4.16 & 0.00 \\
\hline T1 Formal Faculty Support & 0.35 & 0.17 & 0.28 & 2.09 & 0.04 \\
\hline T1 Informal Faculty Support & -0.05 & 0.14 & -0.05 & -0.37 & 0.72 \\
\hline T1 Behavioral Engagement (Effort) & 0.20 & 0.14 & 0.20 & 1.47 & 0.15 \\
\hline Private Institution (Regression Model) & \multicolumn{5}{|c|}{$\mathrm{R}^{2}=0.199 ; \mathrm{F}=2.31 ; N=32 ; p=0.10$} \\
\hline Research Institution (Regression Model) & \multicolumn{5}{|c|}{$\mathrm{R}^{2}=26.3 ; \mathrm{F}=27.5 ; N=240 ; p=0.000$} \\
\hline Constant & 0.49 & 0.06 & & 0.47 & 7.98 \\
\hline T1 Formal Faculty Support & 0.06 & 0.06 & 0.06 & 0.97 & 0.34 \\
\hline T1 Informal Faculty Support & 0.07 & 0.06 & 0.07 & 1.15 & 0.25 \\
\hline T1 Behavioral Engagement (Effort) & 0.49 & 0.06 & 0.47 & 7.98 & $\mathbf{0 . 0 0}$ \\
\hline Teaching Institution (Regression Model) & \multicolumn{5}{|c|}{$\mathrm{R}^{2}=0.224 ; \mathrm{F}=9.13 ; N=99 ; p=0.000$} \\
\hline Constant & 8.31 & 2.52 & & 3.30 & 0.001 \\
\hline T1 Formal Faculty Support & -0.01 & 0.12 & -0.01 & -0.06 & 0.95 \\
\hline T1 Informal Faculty Support & 0.05 & 0.14 & 0.04 & 0.36 & 0.72 \\
\hline T1 Behavioral Engagement (Effort) & 0.55 & 0.12 & 0.46 & 4.59 & $\mathbf{0 . 0 0}$ \\
\hline Women's College (Regression Model & \multicolumn{5}{|c|}{$\mathrm{R}^{2}=0.039 ; \mathrm{F}=12.3 ; N=35 ; p=0.06$} \\
\hline
\end{tabular}


Table 6: Prediction of Behavioral Engagement (Participation) by Faculty Support

\begin{tabular}{|c|c|c|c|c|c|}
\hline & B & SE & $\beta$ & $\mathrm{T}$ & $p$ \\
\hline HBCU Institution (Regression Model) & \multicolumn{5}{|c|}{$\mathrm{R}^{2}=0.242 ; \mathrm{F}=7.24 ; N=72 ; p<0.000$} \\
\hline Constant & 3.49 & 1.14 & & 3.07 & 0.00 \\
\hline T1 Formal Faculty Support & 0.05 & 0.08 & 0.08 & 0.64 & 0.53 \\
\hline T1 Informal Faculty Support & 0.07 & 0.06 & 0.16 & 1.27 & 0.21 \\
\hline T1 Behavioral Engagement (Participation) & 0.33 & 0.11 & 0.36 & 3.00 & $\mathbf{0 . 0 0}$ \\
\hline Private Institution (Regression Model) & \multicolumn{5}{|c|}{$R^{2}=0.221 ; F=2.64 ; N=32 ; p=0.07$} \\
\hline Research Institution (Regression Model) & \multicolumn{5}{|c|}{$\mathrm{R}^{2}=0.272 ; \mathrm{F}=29.43 ; N=240 ; \mathrm{p}=0.000$} \\
\hline Constant & 3.15 & 0.66 & & 4.78 & 0.00 \\
\hline T1 Formal Faculty Support & -0.05 & 0.03 & -0.08 & -1.48 & 0.14 \\
\hline T1 Informal Faculty Support & 0.10 & 0.03 & 0.20 & 3.20 & $\mathbf{0 . 0 0}$ \\
\hline T1 Behavioral Engagement (Participation) & 0.44 & 0.07 & 0.41 & 6.82 & 0.00 \\
\hline Teaching Institution (Regression Model) & \multicolumn{5}{|c|}{$\mathrm{R}^{2}=0.236 ; \mathrm{F}=9.80 ; N=99 ; p=0.000$} \\
\hline Constant & 2.86 & 1.03 & & 2.77 & 0.01 \\
\hline T1 Formal Faculty Support & -0.05 & 0.06 & -0.09 & -0.88 & 0.38 \\
\hline T1 Informal Faculty Support & 0.09 & 0.07 & 0.14 & 1.35 & 0.18 \\
\hline T1 Behavioral Engagement (Participation) & 0.56 & 0.13 & 0.45 & 4.30 & 0.00 \\
\hline Women's College (Regression Model) & \multicolumn{5}{|c|}{$\mathrm{R}^{2}=0.48 ; \mathrm{F}=9.58 ; N=35 ; p=0.000$} \\
\hline Constant & 4.93 & 2.32 & & 2.13 & 0.04 \\
\hline T1 Formal Faculty Support & -0.14 & 0.13 & -0.15 & -1.10 & 0.28 \\
\hline T1 Informal Faculty Support & 0.09 & 0.10 & 0.15 & 0.88 & 0.39 \\
\hline T1 Behavioral Engagement (Participation) & 0.54 & 0.15 & 0.60 & 3.57 & $\mathbf{0 . 0 0}$ \\
\hline
\end{tabular}


Table 7: Prediction of Emotional Engagement (Positive) by Faculty Support

\begin{tabular}{|c|c|c|c|c|c|}
\hline & B & SE & $\beta$ & $\mathrm{t}$ & $P$ \\
\hline HBCU Institution (Regression Model) & \multicolumn{5}{|c|}{$\mathrm{R}^{2}=0.344 ; \mathrm{F}=11.91 ; N=72 ; p<0.000$} \\
\hline Constant & 5.65 & 3.19 & & 1.72 & 0.08 \\
\hline T1 Formal Faculty Support & 0.47 & 0.20 & 0.29 & 2.37 & 0.02 \\
\hline T1 Informal Faculty Support & -0.21 & 0.15 & -0.16 & -1.37 & 0.18 \\
\hline T1 Emotional Engagement (Positive) & 0.56 & 0.15 & 0.46 & 3.66 & 0.00 \\
\hline Private Institution (Regression Model) & \multicolumn{5}{|c|}{$\mathrm{R}^{2}=0.155 ; \mathrm{F}=1.71 ; N=32 ; p=0.188$} \\
\hline Research Institution (Regression Model) & \multicolumn{5}{|c|}{$\mathrm{R}^{2}=0.232 ; \mathrm{F}=23.82 ; N=240 ; \mathrm{p}<0.000$} \\
\hline Constant & 10.3 & 1.61 & & 6.39 & 0.00 \\
\hline T1 Formal Faculty Support & 0.04 & 0.07 & 0.03 & 0.51 & 0.61 \\
\hline T1 Informal Faculty Support & 0.15 & 0.06 & 0.14 & 2.34 & 0.02 \\
\hline T1 Emotional Engagement (Positive) & 0.44 & 0.07 & 0.40 & 6.37 & 0.00 \\
\hline Teaching Institution (Regression Model) & \multicolumn{5}{|c|}{$\mathrm{R}^{2}=0.270 ; \mathrm{F}=11.83 ; N=99 ; p<0.000$} \\
\hline Constant & 7.02 & 2.95 & & 2.38 & 0.02 \\
\hline T1 Formal Faculty Support & 0.26 & 0.13 & 0.21 & 2.05 & 0.04 \\
\hline T1 Informal Faculty Support & 0.25 & 0.15 & 0.17 & 1.65 & 0.10 \\
\hline T1 Emotional Engagement (Positive) & 0.35 & 0.14 & 0.26 & 2.51 & 0.01 \\
\hline Women's College (Regression Model) & \multicolumn{5}{|c|}{$\mathrm{R}^{2}=0.378 ; \mathrm{F}=6.29 ; N=35 ; \mathrm{p}=.002$} \\
\hline Constant & 4.56 & 5.20 & & 0.88 & 0.39 \\
\hline T1 Formal Faculty Support & 0.41 & 0.24 & 0.25 & 1.71 & 0.10 \\
\hline T1 Informal Faculty Support & 0.03 & 0.16 & 0.03 & 0.16 & 0.87 \\
\hline T1 Emotional Engagement (Positive) & 0.50 & 0.15 & 0.53 & 3.40 & $\mathbf{0 . 0 0}$ \\
\hline
\end{tabular}


Table 8: Prediction of Emotional Engagement (Negative) by Faculty Support

\begin{tabular}{|c|c|c|c|c|c|}
\hline & B & SE & $\beta$ & $\mathrm{t}$ & $p$ \\
\hline HBCU Institution (Regression Model) & \multicolumn{5}{|c|}{$\mathrm{R}^{2}=0.247 ; \mathrm{F}=7.45 ; N=72 ; p=0.000$} \\
\hline Constant & 10.10 & 4.25 & & 2.38 & 0.02 \\
\hline T1 Formal Faculty Support & -0.16 & 0.20 & -0.10 & -0.81 & 0.42 \\
\hline T1 Informal Faculty Support & -0.14 & 0.15 & -0.11 & -0.90 & 0.37 \\
\hline T1 Emotional Engagement (Negative) & 0.52 & 0.17 & 0.38 & 3.12 & $\mathbf{0 . 0 0}$ \\
\hline Private Institution (Regression Model) & \multicolumn{5}{|c|}{$\mathrm{R}^{2}=0.253 ; \mathrm{F}=3.16 ; N=32 ; p=0.04$} \\
\hline Constant & 1.20 & 6.30 & & 0.19 & 0.85 \\
\hline T1 Formal Faculty Support & -0.02 & 0.27 & -0.01 & -0.05 & 0.96 \\
\hline T1 Informal Faculty Support & 0.38 & 0.24 & 0.26 & 1.59 & 0.12 \\
\hline T1 Emotional Engagement (Negative) & 0.45 & 0.17 & 0.43 & 2.65 & 0.01 \\
\hline Research Institution (Regression Model) & \multicolumn{5}{|c|}{$\mathrm{R}^{2}=0.235 ; \mathrm{F}=24.13 ; N=240 ; \mathrm{p}=0.000$} \\
\hline Constant & 6.35 & 1.64 & & 3.86 & 0.00 \\
\hline T1 Formal Faculty Support & -.010 & 0.07 & -0.08 & -1.29 & 0.20 \\
\hline T1 Informal Faculty Support & 0.09 & 0.07 & 0.08 & 1.43 & 1.43 \\
\hline T1 Emotional Engagement (Negative) & 0.48 & 0.06 & 0.47 & 8.16 & 0.00 \\
\hline Teaching Institution (Regression Model) & \multicolumn{5}{|c|}{$\mathrm{R}^{2}=0.149 ; \mathrm{F}=5.61 ; N=100 ; p=0.001$} \\
\hline Constant & 3.50 & 2.84 & & 1.23 & 0.22 \\
\hline T1 Formal Faculty Support & 0.16 & 0.16 & 0.16 & 1.36 & 0.18 \\
\hline T1 Informal Faculty Support & -0.05 & 0.13 & -0.05 & -0.42 & 0.68 \\
\hline T1 Emotional Engagement (Negative) & 0.47 & 0.12 & 0.42 & 3.96 & $\mathbf{0 . 0 0}$ \\
\hline Women's College (Regression Model) & \multicolumn{5}{|c|}{$\mathrm{R}^{2}=0.473 ; \mathrm{F}=9.28 ; N=35 ; \mathrm{p}=0.000$} \\
\hline Constant & 0.58 & 4.97 & & 0.12 & 0.91 \\
\hline T1 Formal Faculty Support & 0.24 & 0.24 & 0.14 & 1.00 & 0.33 \\
\hline T1 Informal Faculty Support & -0.11 & 0.14 & -0.10 & -0.74 & 0.46 \\
\hline T1 Emotional Engagement (Negative) & 0.55 & 0.11 & 0.69 & 5.03 & $\mathbf{0 . 0 0}$ \\
\hline
\end{tabular}

